\title{
The CRAB Workshop: Using Forum Theatre and Cognitive Rehearsal to Address Bullying in Nursing Education
}

Kathy O'Flynn-Magee

University of British Columbia, kathy.oflynnmagee@ubc.ca

Patricia Rodney

University of British Columbia, Vancouver, paddy.rodney@ubc.ca

Skye Maitland

University of British Columbia, skye.maitland@alumni.ubc.ca

Kate Proznick

University of British Columbia, Kate.proznick@alumni.ubc.ca

Hannah Turner

University of British Columbia, hannah.turner@alumni.ubc.ca

Lynne Esson

University of British Columbia, lynne.esson@ubc.ca

Ranjit Dhari

University of British Columbia, Ranjit.dhari@ubc.ca

Amy Fong-Yuk Poon

University of British Columbia, amy.poon@ubc.ca

See next page for additional authors

Follow this and additional works at: https://qane-afı.casn.ca/journal

Part of the Health and Physical Education Commons, and the Nursing Commons

\section{Recommended Citation}

O'Flynn-Magee, Kathy; Rodney, Patricia; Maitland, Skye; Proznick, Kate; Turner, Hannah; Esson, Lynne; Dhari, Ranjit; Poon, Amy Fong-Yuk; Radu, Raluca; and Scholte, Tom (2021) "The CRAB Workshop: Using Forum Theatre and Cognitive Rehearsal to Address Bullying in Nursing Education," Quality Advancement in Nursing Education - Avancées en formation infirmière: Vol. 7: Iss. 2, Article 2.

DOI: https://doi.org/10.17483/2368-6669.1290

This Article is brought to you for free and open access by Quality Advancement in Nursing Education - Avancées en formation infirmière. It has been accepted for inclusion in Quality Advancement in Nursing Education - Avancées en formation infirmière by an authorized editor of Quality Advancement in Nursing Education - Avancées en formation infirmière. 


\section{The CRAB Workshop: Using Forum Theatre and Cognitive Rehearsal to Address Bullying in Nursing Education}

\section{Cover Page Footnote}

Thank you to Agnes Choi, BSN graduate 2019, for her early work on the concept of embodiment and to Caryn Dooner, BSN graduate 2019, for editorial support on this manuscript. We would like to acknowledge funding support from a 2018-2019 SSHRC Institutional Support Grant (SIG), and a 2019-2020 UBC Teaching and Learning Enhancement Fund (TLEF). Merci à Agnes Choi, qui a terminé son baccalauréat en sciences infirmières en 2019, pour ses travaux préliminaires sur le concept d'embodiment [intégration physique], et à Caryn Dooner, qui a aussi terminé son baccalauréat en sciences infirmières en 2019, pour le soutien qu'elle nous a offert lors de la rédaction de cet article. Nous tenons à préciser que nous avons reçu une subvention institutionnelle 2018-2019 du Conseil de recherches en sciences humaines (CRSH) ainsi qu'un soutien financier du Fonds pour l'amélioration de l'enseignement et de l'apprentissage 2019-2020 de la UBC (University of British Columbia).

\section{Authors}

Kathy O'Flynn-Magee, Patricia Rodney, Skye Maitland, Kate Proznick, Hannah Turner, Lynne Esson, Ranjit Dhari, Amy Fong-Yuk Poon, Raluca Radu, and Tom Scholte 


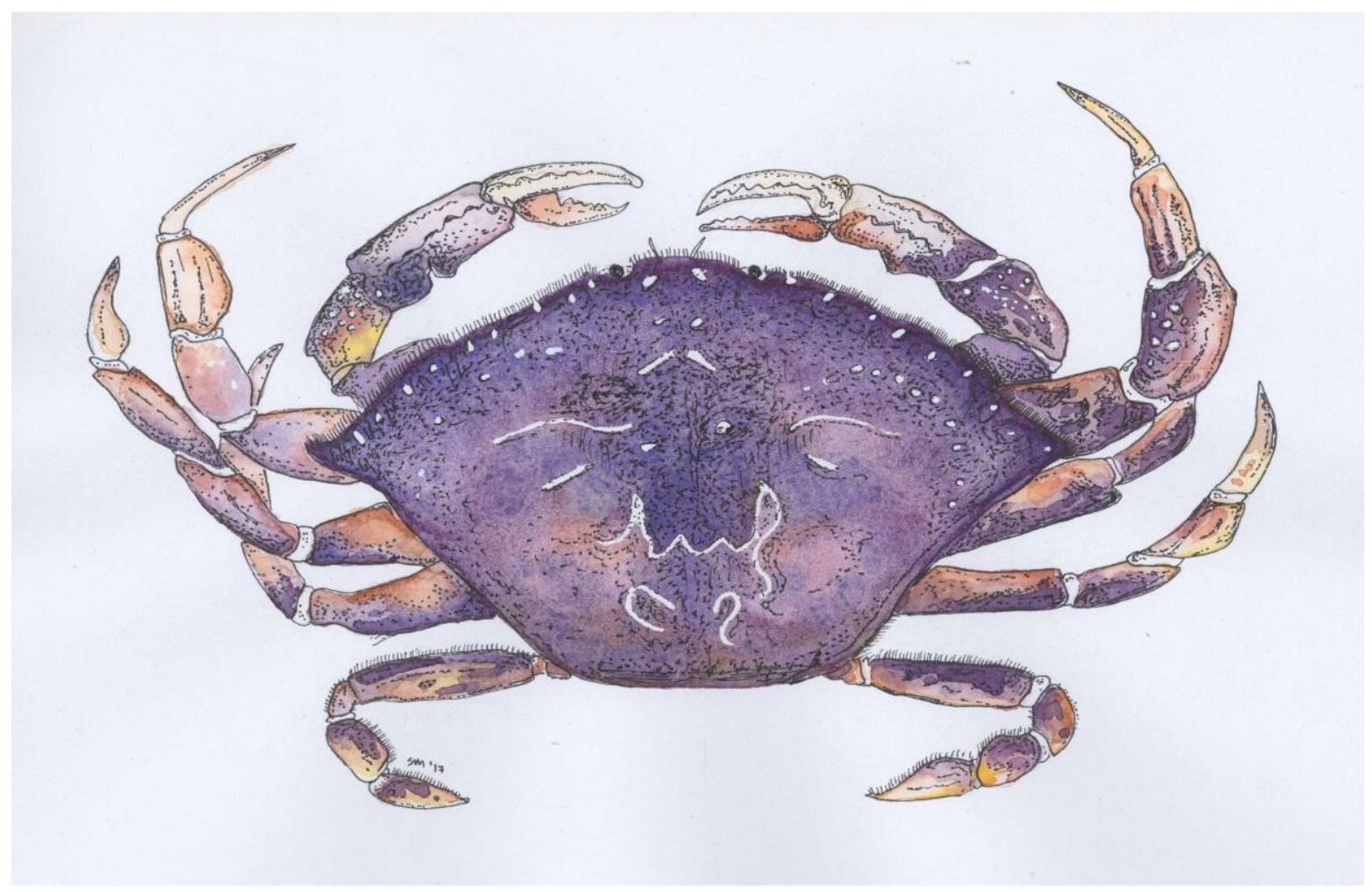

Original watercolour by Skye Maitland (UBC BSN, 2018) for the CRAB Project

\section{Background}

Bullying is known to be rampant among health care workers, and its alarming prevalence in both nursing practice and nursing education programs is well documented (see, for example, Bowllan, 2015; Budden et al., 2017; Clark et al., 2012; Daly et al., 2020; Fehr \& Seibel, 2016; Griffin, 2004; Gillespie et al., 2017; Jack et al., 2018; Seibel, 2014). We are a student-and-faculty group who have been creating a number of initiatives within our overall Cognitive Rehearsal to Address Bullying (CRAB) project to address bullying in nursing education. Pre-licensure students were hired as research assistants and one graduate nursing student was involved as a research coordinator. Illustrating their commitment to this work, many students who have since graduated continue to be involved as co-authors of publications (as is the case in this paper, with five graduated students on the author list). In earlier work, we developed an ethical and relational action framework to address bullying in nursing (Figure 1; O'Flynn-Magee et al., 2020) consisting of three pillars: (a) policy, (b) education, and (c) clinical practice partnerships. 


\section{Figure 1}

An Ethical and Relational Action Framework

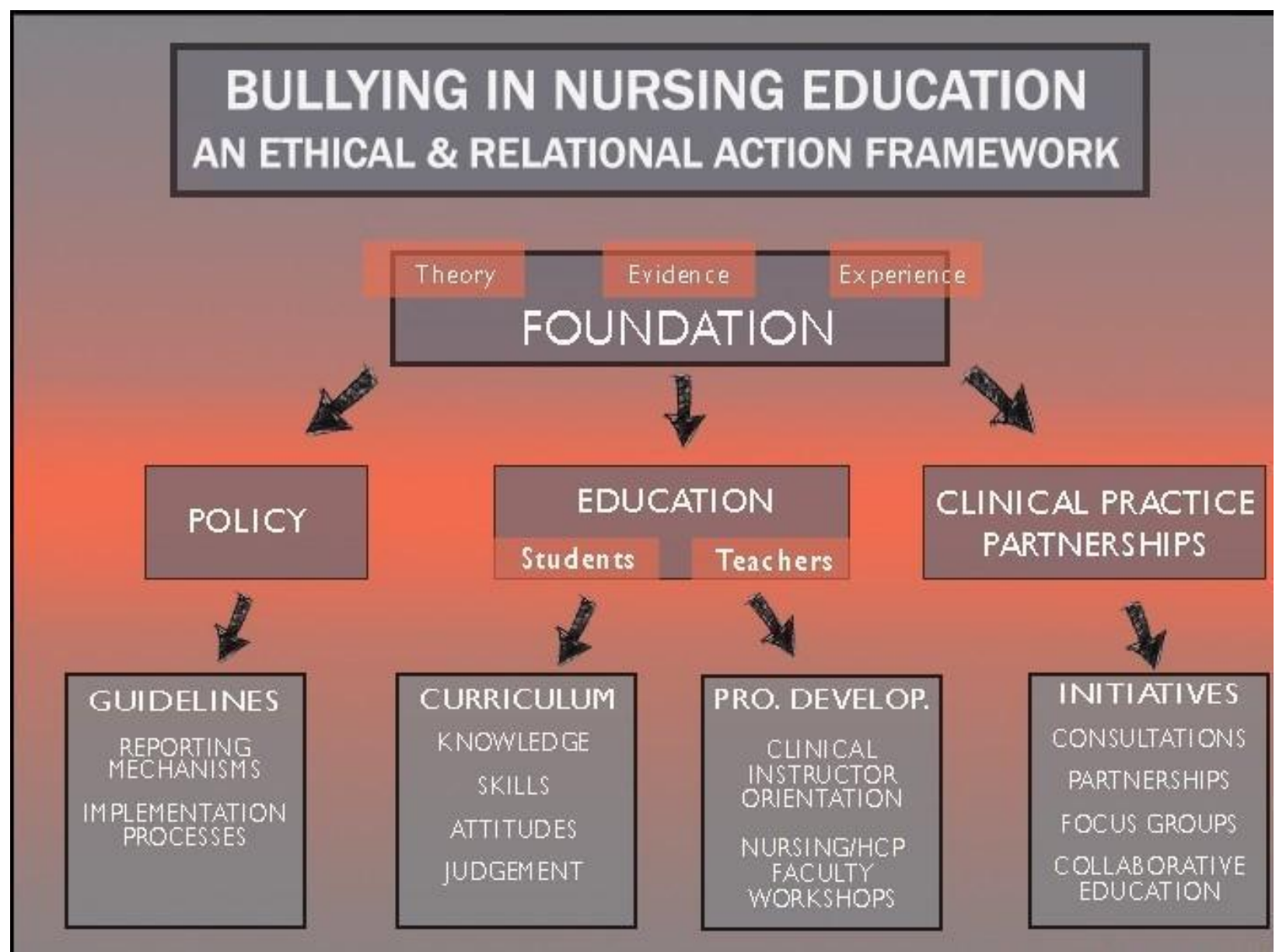

Source: O’Flynn-Magee et al., 2020.

Our initial work focused on the policy pillar of the framework to create a set of procedures to guide students and faculty if the former witnessed or experienced bullying (O'FlynnMagee et al., 2020). This initial work was grounded in a formal request from students to create a policy such as the set of procedures we developed. In this paper, we explore the student component of the education pillar of the framework, which we named the CRAB Workshop. The focus of the CRAB Workshop was to offer skills-based approaches to 120 pre-licensure nursing students to use in response to situations of bullying. We wanted to provide students with active learning (Bonwell \& Eison, 1991; Sharoff, 2019) opportunities through pedagogically sound and theoretically grounded approaches. With this in mind, we used a number of participatory learning activities to co-create a safe(r) learning space and to encourage students to engage in active and embodied learning. Here, the use of the term safe( $r)$, rather than simply safe, acknowledges that while a safe space cannot be guaranteed for all, and safety can be experienced differently by individuals, the intention was to develop an environment that was as safe as possible for participant engagement (Deller, 2019; Mental Health Commission of Canada [MHCC], 2019). 


\section{Theoretical Underpinnings of the CRAB Workshop}

The CRAB Project was grounded in Canadian and international nursing ethics principles (e.g., via the code of ethics of the Canadian Nurses Association, 2017; International Council of Nurses, 2012), theoretical underpinnings of relational inquiry (Hartrick Doane \& Varcoe, 2015), and critical notions of power and oppression (Boal, 1985; Freire, 2000). Nursing ethics and relational inquiry were ideal lenses for this project because they invited us to consider what was happening versus what ought to be happening. These lenses shaped our understanding of the role of power and the meaning of bullying for all involved. We take the view of power as conceptualized by Paulo Freire (2000) in the context of education as something that needs to be shared between teachers and learners to (a) mitigate the effects of oppression, both external and internalized; (b) cultivate the process of "conscientization"; and (c) acknowledge the existence and support the development of human agency. Freire's (2000) and Hartrick Doane and Varcoe's (2015) theoretical perspectives underpin both the role of power and oppression in relational interactions and the different levels at which bullying can occur, from the individual to the organizational and societal. Acknowledging the existence of bullying at varying levels allows parties to move beyond the individuals engaged in a bullying encounter to recognize and act on bullying as an organizational problem. In so doing, both individual and institutional power can be addressed (Hodgins et al., 2020).

\section{Theoretical Underpinnings of Forum Theatre and Cognitive Rehearsal}

Pedagogically, we drew on cognitive rehearsal (Griffin, 2004; Griffin \& Clark, 2014) and forum theatre (Boal, 1985; Diamond, 2007) to design and enact the CRAB Workshop. Cognitive rehearsal has been used for anti-bullying education in nursing for over 15 years (Griffin, 2004), and theatre is acknowledged in the literature as a dynamic and effective approach to use in the classroom for addressing topics such as communication, bullying, power, status, and conflict (Middlewick et al., 2012; Taylor \& Taylor, 2017).

The structure of the CRAB Workshop drew on forum theatre, a subcategory of David Diamond's Theatre for Living work (Diamond, 2007), in which the focus is on supporting communities to address social justice issues through the medium of theatre (D. Diamond. personal communication, July 27, 2017, August 17, 2018). According to Diamond (2007),

Forum Theatre is a form of participatory theatre developed by Boal. It is an opportunity for creative community-based dialogue. The theatre is created and performed by community members who are living the issues under investigation. Workshop participants create a short play, which is performed once all the way through, so the audience can see the situation and the problems presented. The story builds to a crisis, and stops there, offering no solutions... The play is then run again, with audience members able to freeze the action at any point... come into the playing area, replace the... actor and try out [their] idea. The other actors respond in character. This is called an intervention. (p. 39)

Although Diamond's (2007) teachings are based on Augusto Boal's (1985) Theatre of the Oppressed, they move well beyond the binary of oppressed and oppressor to welcome the voice(s) of all involved and to explicate the context(s) in which situations are located, thus making "space to investigate the fears, desires, and motivations of the oppressor-with integrity" (p. 38). Taking the time to explore the social determinants underpinning the behaviour of a so-called oppressor can often reveal further systemic complexities impinging upon the specific incident of oppression under investigation. This approach was relevant because we wanted to ensure that the CRAB 
Workshop moved beyond the notion of bullying as simply an interpersonal encounter. Specifically, we wanted to avoid implementing a workshop that focused on blame at the individual level. Locating bullying interactions within the realistic and complex context of health care reminds students and other parties that to understand bullying, we must first recognize and acknowledge the educational and systemic health care contexts in which it occurs. Such contexts arise from structural and organizational barriers that include, for example, heavy workloads, lengthy nursing shifts, acutely ill patients, high stakes of life and death, worried families, staff sick calls, learners from a variety of health care professional education programs, and a culture that seems to normalize bullying (for critical analyses of the contexts in which bullying occurs, see, for example, Croft \& Cash, 2012; Hodgins et al., 2020; Hutchinson, 2013; Hutchinson \& Jackson, 2015; Hutchinson et al., 2006; Hutchinson et al., 2010).

Forum theatre was the predominant approach used in the CRAB Workshop, but we also drew on cognitive rehearsal as an accompanying activity. Cognitive rehearsal requires individuals to refrain from responding reactively to a situation so that they allow themselves time to consciously process their responses. They draw on previously rehearsed scripts in a thoughtful manner (Griffin, 2004; Griffin \& Clark, 2014). We created original scripts in accordance with Griffin's (2004) approach and, at the completion of our Workshop, provided students with an outthe-door pamphlet containing guided scripts for possible responses to a variety of scenarios not covered in the Workshop (see Appendix A). In essence, the CRAB Workshop used both cognitive rehearsal (which, through its use of scripts, is a deductive approach) and forum theatre, which invites students to inductively create responses to bullying and try their responses out during reiterations of a performance. It is this combination of forum theatre and cognitive rehearsal, as well as pre-theatre activities described later in this paper, that allowed students to embody the approaches being practiced.

Batacharya and Wong (2018) describe embodied learning as that which occurs within body experiences and how those experiences relate to the world around us. These authors draw on the work of the late Roxana $\mathrm{Ng}$, a feminist and anti-racist scholar, to emphasize her view that the body is "at the forefront of knowledge construction" (Learning: The Work of Roxana Ng section, para. 6) and they cite $\mathrm{Ng}$ directly when explaining that body experience has a role in "enabling, limiting, and mediating the creation of knowledge" (Learning: The Work of Roxana Ng section, para. 5). Stolz (2015) emphasizes that embodied learning is different from the more traditional understandings of learning as occurring through psychological or cognitive models-conceptual understandings within which the body is given little acknowledgement. Importantly, Stolz reminds us that

We cannot make contact with the world just by thinking about it, but through experiencing it with senses, acting in it, in ways that range from the most complex to the most primitive un-reflective movements. Hence, the idea of embodied learning within the educational sense involves coming to know ourselves and the world around us better neither as an abstract object nor as an instrument, but as a "lived body" subject that senses and does the sensing in a meaningful way. (p. 4)

Incidences of bullying are particularly loaded with somatic immediacy and intensity. Therefore, the premise of our work has been that embodied learning opportunities enable students to better understand bullying interactions, to empathize with those involved, and to support students to develop their confidence and competence to address bullying. The design of the Workshop was aimed at supporting these opportunities. 


\section{Design of the CRAB Workshop}

In what we came to think of as a "script to stage" format, the CRAB Workshop gave the student audience an opportunity to observe a scripted bullying scenario performed by two actors. The scenario (see Appendix B) was based on clinical events recounted by students involved in the project. Actors played the role of a registered nurse (RN) and a student. Initially, the scenario was performed in its entirety without interruption. Then, the actors resumed for a second run and the student audience was invited to freeze the performance to replace the student character if they believed they could step in and offer something constructive to the interaction (Diamond, 2007). As guided by the work of Diamond, students were discouraged from engaging in "magical thinking" that would enable them to create "amazing changes" simply by taking on the role. Instead, they were guided to remain in character and bring their authentic self to that role so that contributions could be grounded, realistic, and attainable for students in the future. Students received no formal training in advance but did attend an introductory lecture entitled "Communicating in Challenging Contexts" in which there was purposeful focus on bullying content and assigned pre-readings (Fehr \& Seibel, 2016; Jackson et al., 2011), which are noted with an asterisk in the reference list. The content related to bullying included an overview of bullying, its prevalence in nursing education, a way of understanding the nature of bullying, an unpacking of assigned readings, and several details about the CRAB Project and Workshop.

The CRAB Workshop was designed by our faculty-student team and was delivered in eight small-group three-hour sessions of 15 students each. We based student numbers on our capacity to recruit RN actors and faculty facilitators. We recruited RN actors through our alumni database, as well as individually through an invitational email from the primary author. To set the stage, the design of this Workshop first attempted to establish a safe(r) space for students to engage with this charged topic. With this in mind, we opened the Workshop with an invitation for students to engage in a Power Shuffle, designed to highlight bullying. The Power Shuffle, sometimes referred to as a Privilege Walk, is an activity that has historically been used to raise participant consciousness to discrepancies of privilege and power (Layne \& Chiu, 2016). Student and faculty participants were invited to step forward or backward according to their experiences related to pre-designed questions about bullying (see Appendix C). Our aim was to make visible the commonalities within the group related to experiences of bullying and to offer students an opportunity to actively engage and embody the activity as a warm-up for what was to come. However, McIntosh (1989) cautions that a Privilege Walk may situate participants in only one aspect of their identity. Hence, other approaches to participant engagement throughout the workshop included "permission to pass," room for discussion, chances to debrief, and an opportunity for informal feedback. We considered these approaches to participant engagement as ways of inviting voluntary dialogue and ultimately fostering safe(r) spaces.

Next, each CRAB Workshop was facilitated (joked in forum theatre language) by a faculty member and supported by two volunteer actors. To offer an insider's lens to the Workshop, and to collaborate with practice partners, all actors were RNs. A colleague from the Department of Theatre and Film - who is a university professor, professional actor, director, and forum theatre expert-provided an interactive orientation preparatory session for facilitators and actors in advance of the Workshop.

The advanced preparation was especially important for faculty facilitators and actors because it gave the actors time to rehearse with expert guidance and afforded facilitators a chance to observe the joker in action. Important aspects of this preparation included learning about, and 
engaging in, physical warm-up activities, enactment of the scenario with several opportunities to offer an intervention, explanations of how and why the joker unpacked what was happening, debriefings, and enough time for questions and answers. In forum theatre, the role of the joker is to set the tone for what is to come, engage the audience, motivate their participation, help to unpack hidden thoughts of the actors, and debrief the experiences with actors and volunteers in the presence of the audience. Some of the ways in which the joker might engage the audience include asking them to reflect on, and respond to, a bullying encounter in an environment that is likely safer than a real-life situation, as well as by asking volunteer actors to share their wishes or wants for the scenario. The skill of the joker, like any effective facilitator, is to appreciate silence and to know when, why, and how to ask a question and to guide the discussion that follows. Once this debriefing is complete, the joker thanks the volunteer and the process begins again with a new volunteer choosing where in the performance they would like to start their intervention. The essential debriefings usually occur after each intervention, as well as a final one at the completion of the Workshop. These debriefings were crucial in supporting rich discussions and key takeaways from the scenario. As well, they offered a space for RN actors to share their perspectives, something that students said was extremely useful. Afterwards, students were invited to a focus group to share their perspectives of the effectiveness of the Workshop. Although we had planned for a pilot qualitative description study, the low number of participants redirected the authors to share potential findings as feedback.

\section{Implications for Future Nursing Education}

There are implications of using forum theatre as a pedagogy for nursing education at the levels of student, instructor, and organization. As an arts-based pedagogy (ABP) (Rieger \& Chernomas, 2013), forum theatre may be a novel and possibly intimidating approach for educators or students or both. Indeed, Rieger et al. (2020) reported that $20 \%$ of students in their study found ABP to be "a waste of time" (p. 4). Although many of the students who completed the CRAB Workshop provided positive feedback about their experiences, others expressed more negative perspectives.

First, for students it can be daunting to consider going on stage to take on a challenging situation in front of their peers. Student feedback highlighted the importance of creating and maintaining a safe(r) space in which to engage with the processes and content embedded in the Workshop. While the physical space (e.g., the size and layout of the room) influenced some aspects of the experience, it was the psychological space that stood out as being of utmost importance. In particular, student feedback linked safe(r) psychological space to their willingness and capacity to participate in the introductory workshop activities and to feel comfortable and confident enough to step up and assume the role of an actor. In co-creating a safe(r) space (Deller, 2019; MHCC, 2019), our intent was to ensure that students could pass on the Workshop so that they would not feel pressured into participating. For the future, it will be important to provide students with more preparation before engaging in forum theatre. They need to have bullying content, as well as some explanation about, and direction for, engaging in forum theatre. One possible option could be to engage in practice forum theatres so that students are given the opportunity to try out the process before the workshop. It would also be helpful for students to know in advance that they will have control over their participation on stage.

Second, faculty facilitators and RN actors require preparation from an expert in the field so that they can feel confident about, and be effective in, their role as facilitators and actors. For our project, having a colleague from our university's Department of Film and Theatre facilitate 
preparation for both groups was advantageous and essential because it introduced facilitators and actors to forum theatre as a pedagogy and provided direction for their roles during the Workshop. We found an added benefit was the development and continuation of strong partnerships between theatre faculty and nursing faculty.

Although the process worked well, it was not without some challenges. A small number of actors and facilitators were unable to attend the orientation and it resulted in inconsistencies in the Workshop processes across the groups. For example, in one group, all students were expected to offer an intervention on stage whereas other groups encountered a "feel free to pass" approach. For the future, we recommend that orientation sessions are integrated to ensure that actors and facilitators are well prepared and students engage in similar processes across groups.

Third, for education and health care institutions, forum theatre is a time- and resourceheavy approach and requires buy-in from all parties, including leaders who oversee curricula, staffing, and budget. In our project with a class of 120 pre-licensure students, we delivered eight small-group three-hour sessions of 15 students each. This process entailed much planning and the professional generosity of eight faculty facilitators and 16 RNs for the four-hour orientation, threehour Workshop, preparation time, and engagement in a debriefing after the session. For the future, it would lighten the heavy workloads of both groups if faculty facilitators could be formally assigned to the course for 10 hours each and if the volunteer RNs were provided with some time off to partner with colleagues at the university. Such a proposal is feasible if academic and practice leaders are committed to anti-bullying education through arts-based pedagogies, including the outcomes of creative, active, and embodied learning.

\section{Lessons Learned and Recommendations}

Our student-faculty team learned many lessons from engaging in forum theatre and cognitive rehearsal. The following seven points encompass our recommendations for educators (including ourselves) who may want to engage in forum theatre or cognitive rehearsal in the future.

1. Preparation is key to support students, faculty facilitators, and RN volunteer actors. Orientation for facilitators, actors, and students should be mandatory. Priming students through an orientation would be advantageous for all involved, especially around building a space founded on safety and transparency so that students will know what to expect during the Workshop. Faculty facilitators and RN actors can benefit greatly from some preparation with an expert joker. This expertise is invaluable and can go a long way to ensuring that workshops are successful. If an institution does not have such expertise, it would be wise to explore community resources to support the process. One upcoming project that our team anticipate completing in 2021 is a train-the-trainer movie to guide teachers in the use of forum theatre. This will be freely available at letsact.ca

2. The importance of a safe(r) space (Deller, 2019; MHCC, 2019) cannot be overemphasized and it should include setting the stage to co-create a positive learning environment, using warm-up activities, giving permission to pass, not forcing anyone to participate on stage, and securing the best physical space. Some students in our workshops felt compelled to step up more than once because of the reluctance of others to participate. We recommend having a discussion with students before the Workshop to support students' informed and voluntary participation and to ensure they are aware of the potential benefits of active involvement for both them and their peers. As with any safe(r) space, it is crucial to recognize that the safety of one individual may represent a lack of safety for another 
(Anderson, \& Riley, 2020). As educators, we are reminded of the need to give students control over their participation. Safer spaces to teach sensitive topics are "a disciplinary and institutional responsibility rather than simply the duty of a few passionate and committed educators" (Heath et al., 2017, p. 6).

3. Invite and support RNs to be the actors. Students described having RN actors as one of the most positive aspects of the workshop. In many groups, the actors engaged in discussions and debriefings and their authenticity was visible, often giving students contextual insights about why bullying might occur even though the RN may be a strong student advocate. When inviting RNs to join the workshops as actors, it is equally important to consider reaching out to a diverse group of nursing professionals, including from various practice backgrounds, to enrich the overall student experiences.

4. Consider using more than one scenario because giving students more detail and drama with which to work may enhance their confidence to participate on stage (Burton \& O'Toole, 2015). There is a fine balance between repetition and saturation of a single scenario.

5. Be thoughtful about how cognitive rehearsal (Griffin, 2004; Griffin \& Clark, 2014) is integrated into the workshops. Initially, we created a pamphlet that students received as they left the workshop. The following year, we posted the pamphlet on the online learning management system. Neither process facilitated an effective integration. We recommend considering ways to draw on cognitive rehearsal more formally so that students can actively practice the scripts with guidance (see Appendix A for examples in the resource we provided to students).

6. There is potential risk for everyone. Make sure there are resources for all involved in case the Workshops are triggering (Public Health Agency of Canada, 2018). It is likely wise to caution everyone in advance and encourage individuals to reach out for support as needed. For example, it would be helpful to designate a faculty member to whom students could go as needed following the Workshop.

7. Find ways to incorporate Forum Theatre and other ABP into nursing curricula at the prelicensure, graduate, and professional domain levels. This process will require buy-in from academic and practice leaders. Evaluate Workshops and explore future options to disseminate findings and support adoption into clinical settings as appropriate. This approach could include new graduate nurses' orientations, as well as support of ongoing professional development of practising clinical nurses of all designations. This would require collaboration between the academic institution and the health care partners. We believe that our collaboration with RN actors was a small step in this direction.

\section{Conclusion}

Together with cognitive rehearsal, we found that the use of forum theatre was an innovative approach to supporting students in addressing bullying if they witness or experience it. As a pedagogy, forum theatre is a collaborative and complex process with the potential to promote active and embodied learning in a safe(r) space. Our experience emphasized the importance of support from and collaboration with forum theatre experts as well as RN actors. Although it is a time- and resource-heavy approach, it is our experience that it fosters creative and active learning and is well worth the investment. 


\section{References}

Anderson, L., \& Riley, L. (2020). Crafting safer spaces for teaching about race and intersectionality in Australian indigenous studies. The Australian Journal of Indigenous Education, 1-8. https://doi.org/10.1017/jie.2020.8

Batacharya, S., \& Wong, Y. L. R. (Eds.). (2018). Introduction. In Sharing breath: Embodied learning and decolonization. Athabasca University Press.

Boal, A. (1985). Theatre of the oppressed. Theatre Communications Group.

Bonwell, C. C., \& Eison, J. A. (1991). Active learning: Creating excitement in the classroom (ASHE-ERIC Higher Education Rep. No. 1). George Washington University, School of Education and Human Development. https://files.eric.ed.gov/fulltext/ED336049.pdf

Bowllan, N. M. (2015). Nursing students' experience of bullying. Nurse Educator, 40(4), 194198.

Burton, B. \& O'Toole, J. (2015). Enhanced forum theatre: Where Boal's theatre of the oppressed meets process drama in the classroom. Drama Australia Journal, 29(2), 49-57. https://doi.org/10.1080/14452294.2005.11649478

Budden, L. M, Birks, M., Cant, R., Bagley, T., \& Park, T. (2017). Australian nursing students' experience of bullying and/or harassment during clinical placement. Collegian, 24, 125133. https://doi.org/10.1016/j.colegn.2015.11.004

Canadian Nurses Association. (2017). Code of ethics for registered nurses. https://cnaaiic.ca/ /media/cna/page-content/pdf-en/code-of-ethics-2017-edition-secureinteractive.pdf

Clark, C., Kane, D., Rajacich, D., \& Lafreniere, K. (2012). Bullying in undergraduate clinical education. Journal of Nursing Education, 51(5), 269-276. https://doi.org/10.3928/01484834-20120409-01

Croft, R. K., \& Cash, P. A. (2012). Deconstructing contributing factors to bullying and lateral violence in nursing using a postcolonial feminist lens. Contemporary Nurse, 42(2), 226242. https://doi.org/10.5172/conu.2012.42.2.226

Daly, Z., O'Flynn-Magee, \& K., Rodney, P. (2020). A call to revisit and address the histories of bullying in nursing education. Quality Advancement in Nursing Education/Avancées en formation infirmière, 6(3), Article 9. https://doi.org/https://doi.org/10.17483/2368$\underline{6669.1249}$

Deller, R. (2019). Safer spaces. In R. Kina \& U. Gordon (Eds.), Routledge handbook of radical politics (pp. 222-239). Routledge.

Diamond, D. (2007). Theatre for living: The art and science of community-based dialogue. Trafford Publishing.

Fehr, F. C., \& Seibel, L. M. (2016). Cognitive rehearsal training for upskilling undergraduate nursing students against bullying: A qualitative pilot study. Quality Advancement in Nursing Education/Avancées en formation infirmière, 2(1), Article 5. https://doi.org/10.17483/2368-6669.1058

Freire, P. (2000). Pedagogy of the oppressed (50th anniversary ed.). Bloomsbury Publishing. 
Gillespie, G. L., Grubb, P. L., Brown, K., Boesch, M. C., \& Ulrich, D. L. (2017). "Nurses eat their young": A novel bullying educational program for student nurses. Journal of Nursing Education and Practice, 7(7), 11-21. https://doi.org/10.5430/jnep.v7n7p11

Griffin, M. (2004). Teaching cognitive rehearsal as a shield for lateral violence: An intervention for newly licensed nurses. JCE in Nursing, 35(6), 257-263. https://doi.org/10.3928/00220124-20041101-07

Griffin, M., \& Clark, C. (2014). Revisiting cognitive rehearsal as an intervention against incivility and lateral violence in nursing: 10 years later. JCE in Nursing, 45(12), 535542. https://doi.org/10.3928/00220124-20141122-02

Hartrick Doane, G., \& Varcoe, C. (2015). How to nurse: Relational inquiry with individuals and families in changing health and health care contexts. Lippincott, Williams \& Wilkins.

Heath, M., Due, C., Hamood, W., Hutchinson, A., Leiman, T., Maxfield, K., \& Warland, J. (2017). Teaching sensitive material: A multi-disciplinary perspective. Ergo, 4, 5-13.

Hodgins, M., Lewis, D., MacCurtain, S., McNamara, P., Hogan, V., \& Pursell, L. (2020). “. . . A bit of a joke": Policy and workplace bullying. SAGE Open, 1-14. https://doi.org/10.1177/2158244020934493

Hutchinson, M. (2013). Bullying as workgroup manipulation: A model for understanding patterns of victimization and contagion within the workgroup. Journal of Nursing Management, 21(3), 563-571. https://doi.org/10.1111/j.1365-2834.2012.01390.x

Hutchinson, M., \& Jackson, D. (2015). The construction and legitimation of workplace bullying in the public sector: Insight into power dynamics and organisational failures in health and social care. Nursing Inquiry, 22(1), 13-26. https://doi.org/10.1111/nin.12077

Hutchinson, M., Vickers, M., Jackson, D., \& Wilkes, L. (2006). Workplace bullying in nursing: Towards a more critical organisational perspective. Nursing Inquiry, 13(2), 118-126. https://doi.org/10.1111/j.1440-1800.2006.00314.x

Hutchinson, M., Vickers, M., Jackson, D., \& Wilkes, L. (2010). Bullying as circuits of power: An Australian nursing perspective. Administrative Theory \& Praxis, 32(1), 25-47. https://doi.org/10.2753/ATP1084-1806320102

International Council of Nurses. (2012). The ICN code of ethics for nurses. https://www.icn.ch/sites/default/files/inlinefiles/2012_ICN_Codeofethicsfornurses_\%20eng.pdf

Jack, K., Hamshire, C., Harris, W. E., Langan, M., Barrett, N., \& Wibberley, C. (2018). "My mentor didn't speak to me for the first four weeks": Perceived unfairness experienced by nursing students in clinical practice settings. Journal of Clinical Nursing, 27(5-6), 929938. https://doi.org/10.1111/jocn.14015

Jackson, D., Hutchinson, M., Everett, B., Mannix, J., Peters, K., Weaver, R., \& Salamonson, Y. (2011). Struggling for legitimacy: Nursing students' stories of organisational aggression, resilience and resistance. Nursing Inquiry 18(2), 2-10. https://doi.org/10.1111/j.1440$\underline{1800.2011 .00536 . x}$ 
Layne, R., \& Chiu, R. (2016). Peace learner: Cultivating peace and nonviolence in the field of education. Privilege walk lesson plan. https://peacelearner.org/2016/03/14/privilegewalk-lesson-plan/

McIntosh, P. (1989). White privilege: Unpacking the invisible knapsack, and Some notes for facilitators. National Seed Project; Wellesley Centers for Women, Wellesley College. https://nationalseedproject.org/Key-SEED-Texts/white-privilege-unpacking-theinvisible-knapsack

Mental Health Commission of Canada. (2019). Safer space guidelines. https://www.mentalhealthcommission.ca/sites/default/files/201903/safer_space_guidelines_mar_2019_eng.pdf

Middlewick, Y., Kettle, J., \& Wilson, J. (2012). Curtains up! Using forum theatre to rehearse the art of communication in healthcare education. Nurse Education in Practice, 12(3), 139142. https://doi.org/10.1016/j.nepr.2011.10.010

O'Flynn-Magee, K., Rodney, P., Pearson, M., Burnay, M., \& Daly, Z. (2020). Interrupting the cycle of bullying witnessed or experienced by nursing students: An ethical and relational action framework. Nurse Education Today, 91, Article 104458. https://doi.org/10.1016/j.nedt.2020.104458

Public Health Agency of Canada. (2018). Trauma and violence-informed approaches to policy and practice. https://www.canada.ca/en/public-health/services/publications/health-riskssafety/trauma-violence-informed-approaches-policy-practice.html

Rieger, K. L., \& Chernomas, W. M. (2013). Arts-based learning: Analysis of the concept for nursing education. International Journal of Nursing Education Scholarship, 10, 1-10. https://doi.org/10.1515/ijnes-2012-0034

Rieger, K. L., \& Chernomas, W. M., McMillan, D. E., \& Morin, F. L. (2020). Navigating creativity within arts-based pedagogy: Implications of a constructivist grounded theory study. Nurse Education Today, 91, 104465.

Seibel, L. M. (2014). For us or against us? Perceptions of faculty bullying of students during undergraduate nursing education clinical experiences. Nursing Education in Practice, 14(3), 271-274. https://doi.org/10.1016/j.nepr.2013.08.013

Sharoff, L. (2019). Creative and innovative online teaching strategies: Facilitation for active participation. Journal of Nursing Education, 16(2). https://doi.org/10.9743/JEO.2019.16.2.9

Stolz, S. A. (2015). Embodied learning. Educational Philosophy and Theory. 47(5), 474-487

Taylor, S. S., \& Taylor, R. A. (2017). Making power visible: Doing theatre-based status work with nursing students. Nurse Education in Practice. 26, 1-5. https://doi.org/10.1016/j.nepr.2017.06.003 


\section{Appendix A}

The CRAB Pamphlet

Why CRAB

Good question! From the beginning, this project has been focused on the role of cognitive rehearsal - that is, the act of rehearsing challenging scenarios in order to shift the way we respond in the future - as a powerful means of preparing us for experiences of bullying throughout our careers as nurses. While we considered the key aspects of this project, the acronym CRAB naturally fell into place.

Once we settled on the acronym, we were reminded of the "crabs-in-the-bucket mentality" metaphor. In our version of this metaphor, the bucket of crabs symbolizes the very culture surrounding bullying in health care, where it pulls at the heels of those who might be seeking growth and learning and, in so doing, contributes to, or sustains, cultures of bullying practice.

Our intention in using this symbol is to remind us that we can engage with cognitive tools to thoughtfully and critically stand apart from this culture of bullying, and in doing so hopefully inspire our peers to follow along. With practice, commitment, and collaboration, we can shift these entrenched cultures of practice

\section{GUIDING PRINCIPLES $1,2,3,4,5$}

The CRAB Workshop, resources, and pamphlet have been informed by the principles of trauma- and violence-informed care (TVIC), effective communication, constructive feedback, relational inquiry, relational practice, forum theatre, and cognitive rehearsal.

- Acknowledge other perspective; listen, understand and encourage.

- Be gentle on the person (including yourself), but hard on the behaviour.

- Address your concerns in a timely, private, and specific manner. Use "I" statements, describing what you want and how you feel.

- Be aware of the context and environment. This includes recognizing the power dynamic that might be influencing the situation.

- Consider that everyone has a history that informs their actions and reactions.

- Move beyond "us" and "them." Exchange reasons for personal experience. Appreciate that bullying in nursing is situated in the broader context of social violence.

- Maximize supports whenever you can.

\footnotetext{
${ }^{1}$ Hartrick Doane, G., \& Varcoe, C. (2015). How to nurse: Relational inquiry with individuals and families in changing health and health care contexts. Lippincott, Williams \& Wilkins.

${ }^{2}$ Johnson as cited in Stein-Parbury, J. (2014). Patient and person: Interpersonal skills in nursing (5th ed.). Elsevier/Churchill Livingstone.

${ }^{3}$ National Health Service. (n.d.). Principles of giving effective feedback. https://www.faculty.londondeanery.ac.uk

${ }^{4}$ University of Delaware. (n.d.). Principles of constructive feedback. https://www.ctal.udel.edu

${ }^{5}$ Diamond, D. (2007). Theatre for living. Trafford Publishing.
} 


\section{SCENARIO ONE}

It's 8:20 a.m. Your primary nurse approaches you (student nurse) and asks, "Why haven't you given your medication yet? You are sooo slow. Here, give it to me,"

INSTEAD OF . . .

"Ahhh!" or "I'm so sorry"

TRY:

"I realize that it's a hectic day and it takes me longer as a student but I'll get it done within the $1 / 2$ hour window. Thanks for offering your help . . . but . . . I'd love to give this one. Can I check in with you once I'm done?"

\section{SCENARIO TWO}

Student: "My patient needs their PRN medication, so I'll just go get it."

Nurse: Hold on. I have it here in my pocket because the patient didn't need it last time.

You can use it now."

Student: "Thanks, but I can't give a med I haven't poured."

Nurse: "You're kidding. That's ridiculous."

Student: "I'm sorry, but ..."

Nurse: "What school are you from?

? That explains it" (*exaggerated sigh*).

\section{INSTEAD OF . .}

"Actually that's not right. Nurses can only give meds they've poured so actually you'll have to give it."

TRY:

"As a student, I can't give a med I haven't poured, but I can go with you to position Mr. A . . "

Later, when an opportunity arises, "I'm curious about your earlier comments. Have you any specific concerns about working with me as a student?"

\section{SCENARIO THREE}

Primary nurse and student are with a post-surgical patient, Mr. A, to assess his wound and change his dressing. The nurse says, "Where did you learn to change a dressing? That is NOT the way to do it."

\section{INSTEAD OF . . .}

Saying nothing, looking at the patient or downwards with embarrassment, and feeling extremely awkward. 
TRY:

"I've observed different ways to approach a dressing change, and I'm trying this one today because other experienced nurses have recommended it as the least awkward way for new nurses to maintain asepsis. Could you guide me in your preferred way?"

Later, follow up with the primary nurse or your CI to address how the feedback was given.

\section{SCENARIO FOUR}

Primary nurse ignores you (student) throughout the shift, doesn't tell you when they are going on break and tells you to report to your CI rather than them. Just before your shift change, your post-surgical patient suddenly starts vomiting uncontrollably. Your CI is off the unit and you don't know what to do. You need someone to help assess the patient. You approach the nurse for help and they say, "Go find your CI-their job is to teach you what to do."

INSTEAD OF . .

"Aren't they your patients also?"

TRY:

"Right now, I'm concerned for the patient because they seem to be deteriorating and they need someone experienced to assess what's going on. Can you help me now, and perhaps we can talk about it later with my CI?" Nurse sighs loudly but comes with you.

\section{OTHER TRICKY SITUATIONS}

If unsure of how to respond in any situation, give yourself some time to reflect on the situation, and talk to a support.

TRY:

"I am not sure what to say right now, but I'd like an opportunity to chat about it when we are back on shift next week. Would you be open to that?"

\section{SUPPORT, SUPPORT, SUPPORT!}

Consider if you want to address challenging behaviors directly or if it would be best to discuss your concerns with your CI or others. Whatever you choose to do, it is important not to do nothing.

\section{REFERENCES/BIBLIOGRAPHY}

EQUIP Health Care (2017). Equity Talk Pocket Cards. Vancouver, BC. Retrieved from www.equiphealthcare.ca

Griffin, M. (2004). Teaching cognitive rehearsal as a shield for lateral violence: an intervention for newly licensed nurses. Journal of Clinical Ethics in Nursing, 35(6), 257-263

\section{CREATORS}

O’Flynn-Magee, K., Rodney, P., Turner, H., Proznick, K., \& Maitland, S. (2017; revised 2018). The CRAB pamphlet. 


\section{Appendix B}

\section{WORKSHOP: FORUM THEATRE \& COGNITIVE REHEARSAL TO ADDRESS BULLYING IN NURSING EDUCATION}

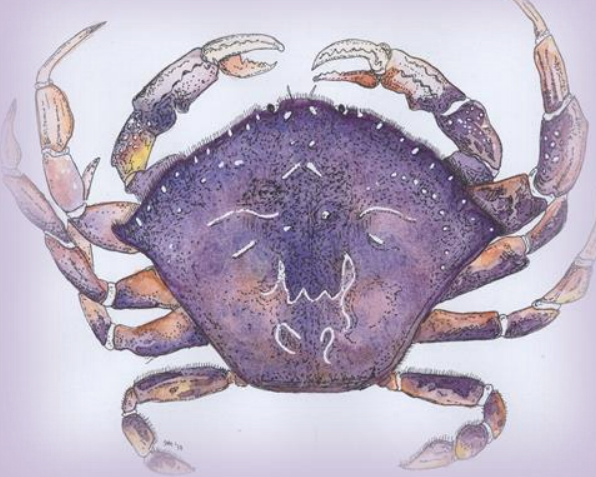

Artist Skye Maitland, BSN grad 2018

\section{LIGHTS, ACTION, CAMERA}

You are a first-term student at the xxx School of Nursing in your 10th week (7th week of clinical practice) of the program. You arrive on the unit for an 8-hour day shift (the 2nd of a twoday set) and you are feeling well prepared and fresh because of 8 solid hours of sleep. You are excited to put into practice your learning from the day before with Ms. T. and Mr. O. The registered nurse (RN) with whom you worked is off shift and you are looking forward to learning lots with a different RN. Today is a day that has you are feeling that your decision to come into nursing is the best decision ever!

Because there have been admissions and transfers overnight, your clinical instructor (CI) changes your assignment so that you will care for one of the patients you had the previous day, Mr. O, and one new patient, Ms. A. You feel nervous because you think that you need more time to prepare for someone new although you remain excited and enthusiastic about the day ahead. Your CI shared their expectation that only manual BPs are to be taken so that you get lots of practice in term 1. You are a little worried that you won't be able to hear your patients' BPs with the manual sphyg because you found it quite challenging the previous day. Your CI is understanding and reassures you that they will support you as needed. But first, they remind you that you need to find your RN and share your plan of care.

As you sit at the desk to complete the kardex, you are thinking about where to find the new $\mathrm{RN}$ so that you can introduce yourself and share your plan when they walk into the report room. What happens next surprises you. Students have the scenario up until this point. 


\section{SCENE 1 ACT 1}

Kelly is sitting at the desk just finishing their review of the kardex when their new RN, Chris, arrives on the unit. Running a little late and just back from days off from working on the "other side" of the unit, Chris appears a little distracted. They explicitly "eye"" the chair that Kelly occupies, causing Kelly to feel flustered and jump up to offer their seat to Chris, who takes it as a "rite of passage" and an expected entitlement. Once seated, Chris pulls the kardex towards them and reaches for their coffee mug that omits a delicious aroma of a fresh brew. Kelly's enthusiasm is unwavering and they eagerly introduce themselves as follows....

Kelly: Hi there, I'm Kelly, a first-term nursing student and I am soooo excited to be paired with you today. I was with your colleague yesterday and we had a great day. I learned so much and I am hoping to use some of that today. I am assigned to two of your patients, Mr. O. and Ms. A. I had Mr. O yesterday but I didn't have Ms. A-I had Mr. T. I did find it hard to hear Mr. O's BP - we have to take them manually so the RN really helped me with that yesterday-just double checked. It was soooo helpful. Could we ....

Chris: Can you stop with all the details! Who did you say you are? (Makes no eye contact and speaks quite abruptly to her.)

Kelly: I'm Kelly, a first-term student

Chris: From where?

Kelly: The program at university xxx — it's an intense program but I'm enjoying it!

Chris: University xxx —oh my goodness (rolls eyes and sighs rather loudly) — that explains it ....

Kelly: (Looks a little crestfallen because of Chris's tone.) SILENCE for a few seconds

Chris: Ok, so you've been here for weeks and you can't do a blood pressure? (tone)

Kelly: Well, I can with the automatic machine but my CI wants us to only do manuals now for the rest of our rotation. I can do it manually as long as you check it.

Chris: Do you know that I've just transferred from working on the other side - this is my first day back and I have a student who cannot take a blood pressure. Mr. O has hypertension! What CAN you do exactly? (Tone is quite dismissive throughout.)

Kelly: Well, I can do full head to toe assessments, vital signs, mobilizing, personal hygiene, communicating effectively ....

Chris: Ok, stop there! It sounds like you cannot do all the vitals if you need someone to check your blood pressures. Look, I need to read the kardex and have my coffee. Quite frankly, I am quickly developing a whopper of a headache, so you need to get going and get your CI to check whatever needs checking. I do not have time or inclination, and your CI is paid to do it.

Kelly: (Looks really crestfallen and moves to leave.) FrEEZE/STOP

Scenario and guidelines created by the CRAB Project Team (O'Flynn-Magee, K., Rodney, P., Proznick, K., Turner, H. Maitland, S., \& Dhari, R., 2017; revised 2018). 


\section{Appendix C}

THE CRAB WORKSHOP

WELCOME/GOALS/INTROS/POWER SHUFFLE

WELCOME

BRIEF ROUND OF INTROS: Name one thing that "makes my heart sing."

$\underline{\text { GUIDELINES }}$

- Confidentiality

- No names of individuals or institutions

- Encouragement to "try it out"

- Invitation to "pass"

- Support, resources, and referrals as needed

\section{POWER SHUFFLE (EMBODIED ACTIVITY)}

Prior to the workshop, facilitators and students view "the privilege walk" example https://www.youtube.com/watch?app=desktop\&v=hD5f8GuNuGQ

\section{POWER SHUFFLE INTRODUCTION:}

- Commonly used activity in anti-oppression workshops.

- Tailored today for the context of bullying in nursing education.

- Idea is to derive a sense of what our knowledge and experience is as a group around bullying.

- No expectation that you HAVE TO participate; our hope is to create a safe(r) space where we may share together and draw upon our experiences to learn and grow as a group.

- You may wish not to step forward or back, that is ok!

- Encourage students to feel open to share about these experiences as we are all working together to identify this important issue and develop creative ways to address this issue.

- Great learning potential by engaging in the physicality (embodiment) of the exercise.

- As in the YouTube PRIVILEGE WALK, students stand in a straight line to begin.

\section{FACILITATOR NOTES:}

Read slowly and PAUSE for time to consider the phrases. 
Step forward if you have a nurse in your family.

Step forward if you have siblings.

Step forward if you're a parent.

Step forward if you feel nervous about this workshop.

Step forward if you did the readings for this workshop.

Step back if you're feeling awkward now.

Step forward if you've ever felt judged unfairly.

Step forward if you've ever been labelled.

Step back if you've judged or labelled someone else unfairly.

Step forward if you love going to clinical.

Step back if you've ever dreaded going to clinical.

Close your eyes and recall a moment in clinical where you may have felt uncomfortable with power/social dynamics and draw upon that context for the next few statements:

Step back if you've witnessed bullying since starting this program.

Stay forward if you are unsure.

Step forward if you intervened or wished you had.

Step forward if you have been bullied in nursing.

Step forward if someone intervened on your behalf or supported you.

Step forward if you wished someone had been there for you.

Step back if you wish you had been better supported.

Step back if you've ever been surprised by your own judgements of another.

Step forward if you've ever been hurt by the words of another.

Step forward if you've ever been supported by the words of another.

Step forward if you've ever advocated for another.

Short de-brief . . . open to the group ... how was that exercise for you?

\section{CREATORS}

Designed by the CRAB Project Team (O’Flynn-Magee, K., Rodney, P., Proznick, K., Turner, H. \& Maitland, S. (2017; revised 2018). 